\title{
Literatura y juego: Las canciones escenificadas infantiles
}

\author{
Pedro C. Cerrillo TORREMocha \\ Dpto. de Filología Hispánica \\ Facultad de Educación y Humanidades \\ Universidad de Castilla-La Mancha. Cuenca
}

\section{RESUMEN}

El autor analiza los contenidos y la estructura organizativa de las canciones escenificadas infantiles (corro, comba, filas, columpio...), que son composiciones que van necesariamente acompañadas de una acción que se representa $o$, cuando menos, de una serie de gestos muy concretos, deteniéndose expresamente en aquellas cancio. nes infantiles en las que sobreviven romances, o partes de romances, de amplia difusión popular en otros tiempos. En el último apartado, el trabajo se refiere al proceso de desaparición que sufren estas composiciones, lo que provoca un aprendizaje diferente de las mismas (previo paso de la oralidad a la escritura) por los niños y niñas de hoy.

Palabras clave: Folklore Infantil, Canciones, Juegos, Romancero, Tradición Oral.

\section{SUMMARY}

The main goal of this paper is to analyze the content and structure of stagey children songs (skipping, rows, swing, playing a game standing in a ring...). These songs are considered to be orally-transmitted compositions, necessarily accompanied by an action that requires either staging or specific body language. I focus on those songs that contain popular and traditional ballads, or parts thereof. Reference is also made to the gradual disappearance of these compositions and the impact of this fact on the way children learn them nowadays, before they are put into writing.

Key words: Children's Folklore, Songs, Games, Collection of Ballads, Oral Tradition.

RDTP, LIX, 2 (2004): 175-194 
Cada generación que pasa se lleva irremisiblemente consigo, para siempre, una parte preciosa de la berencia tradicional; algunos de los viejos temas conservados dejan de cantarse y muchos motivos poéticos de los que adornan los relatos tradicionales caen en el olvido (Catalán, 1970: 173).

Las sociedades desarrolladas actuales le han dado la espalda a la literatura tradicional. El modelo de sociedad en que vivimos ha propiciado la ruptura de la cadena que transmitía, oralmente, las composiciones literarias tradicionales, y que propiciaba su enriquecimiento con la continua aparición de variantes.

La cultura de la oralidad ha cambiado radicalmente en sus formas de comunicación; es muy difícil escuchar hoy, en calles y plazas, de viva voz, de boca a oído, manifestaciones que, en otros tiempos, eran habituales: aguinaldos, leyendas, canciones de siega o de bodas, romances, incluso villancicos. En cualquier caso, son textos que pervivirán como textos literarios, más allá de su primitiva vida oral, puesto que se han recogido, transcrito y fijado; lo que sucede es que, a diferencia de lo que ha pasado con los cuentos (que se han recogido, fijado y versionado en diferentes momentos: recordemos a Perrault, a los Grimm, a Andersen, a Fernán Caballero o a Afanásiev), el folclore poético ha mantenido su vida en la oralidad, es decir lo que ha pervivido son sus variantes orales, pese a que en algunas ocasiones (no tantas como los cuentos) hayan sido recogidas y fijadas por escrito, con un sentido claro de conservación, sobre todo en los últimos años en que se vislumbraba un real peligro de desaparición.

Salvo algunos casos muy particulares (v.g. los "mayos"), la poesia lirica de tradición popular ha quedado reducida a determinados juegos infantiles y a aquellas canciones que los niños aprenden en la escuela. En el caso concreto del Cancionero Popular Infantil es difícil encontrar hoy un grupo de niñas que jueguen en corro imaginando que son reinas de los mares o que, por un día, van a representar el papel de la Viudita del Conde Laurel. La oferta lúdica de la televisión, los juegos electrónicos y las nuevas actividades que se derivan del ordenador se han impuesto a otros juegos que, además, requerían unos espacios que las actuales configuraciones de las ciudades, incluso de muchos pueblos, no pueden ya ofrecer. Antes de la irrupción de la televisión en los hogares españoles, muchas familias, en las largas tardes de invierno, aprovechaban el calor de la estufa o del fogón para contar leyendas y cuentos o para cantar romances, burlas y amores, entreteniendo también a los más pequeños. 
Con la llegada del buen tiempo, los niños aprendían en la calle juegos de diversos tipos, retahílas para sortear, canciones de comba y corro o aplicaban los romances antes aprendidos a sus propios juegos, en un proceso de recreación singular e interesantísimo.

Este hecho, no obstante, no nos debe apartar de la conveniencia de conocer con mayor profundidad esos tipos de composiciones, no sólo porque, con ello, estaremos propiciando su conservación, aunque sea por vía culta, sino también porque ayudaremos a su difusión con criterios más sólidos: me refiero a que no siempre las colecciones y antologías que rescatan canciones tradicionales infantiles para los lectores actuales se apoyan en bases lo suficientemente firmes: en el fondo de esas composiciones, a las que no dudamos en llamar "sonsonetes", "cancioncillas" o "cantinelas" (sin diferenciar, a veces, su significado de un cierto matiz peyorativo), hay toda una serie de elementos lingüísticos y literarios que pasan desapercibidos. El desconocimiento $\multimap$ o el olvido- de ese carácter literario provoca que, en muchas ocasiones, el uso escolar de este tipo de canciones (o de las estructuras que las componen) quede reducido al dictado de meras recetas, muy útiles en un primer momento, pero vacías de contenido cuando llega el momento en que el educando tiene que enfrentarse a estructuras y prácticas lingüisticas más complejas.

CORROS, COMBAS, FILAS, COLUMPIOS...

Las canciones escenificadas son canciones tradicionales (con predominio de elementos líricos, en unos casos, y narrativos, en otros) que, en su origen, tienen un autor individual (casi siempre desconocido), pero que al ser aceptadas enseguida por una colectividad pasan a ser anónimas, enriqueciéndose con variantes que surgen debido a su transmisión oral, a la intervención de la propia colectividad en el proceso de transmisión (quitando, cambiando o añadiendo elementos) y a los diversos tiempos y espacios en que se suelen interpretar.

El estudio literario de las canciones escenificadas plantea un problema ya en su inicio: el que representa la fijación de sus límites y la terminología que emplearemos para su designación. En las antologías y cancioneros existentes podemos encontrarlas agrupadas o diferenciadas en "canciones de comba", "de rueda", "de corro", "de filas", "de columpio", "de grupos",... En otras ocasiones se las conoce con el término más general de "canciones infantiles". Pese a los inconvenientes que conlleva su fijación y su delimitación, parece conveniente realizar un esfuerzo en tal sentido, con el que se evite su posible confusión con otros tipos de com- 
posiciones y con el que, al mismo tiempo, se logre la mayor aproximación a su definición y, con ella, a su caracterización.

Las canciones escenificadas infantiles son composiciones que van, necesariamente, acompañadas de una acción que, en unos casos, se representa (incluso con papeles asumidos por los participantes en ella) y que, en otros, se mima solamente. Da igual que sean interpretadas a la rueda, a la comba, en filas, en grupo o al columpio; da igual que se trate de actuaciones muy concretas (la dola, el burro, el moscardón); incluso algunas de ellas, en ciertos casos, se interpretan de modos distintos, según sea su localización geográfica. De todos modos, la característica principal de estas canciones es su utilización en diferentes actividades grupales, esencialmente lúdicas, que requieren determinados movimientos y gestos; en ese sentido, podríamos considerarlas como el "soporte literario" de esas actividades.

Las acciones que dan lugar a los juegos a que acompañan las canciones escenificadas requieren siempre palabras y gestos para su correcta interpretación; son juegos muy diversos que se podrían agrupar en dos grandes bloques: Los juegos masculinos (dola, burro, pidola, clavo, moscardón), que exigían un esfuerzo mayor y, en algunas ocasiones, podían provocar cierto daño, y los juegos femeninos (corro, comba, columpio, filas), que requerían más habilidad en la mayoría de los casos, aunque algunos de los juegos se interpretaban tanto por chicos como por chicas (pelota, por ejemplo).

Estas canciones han tenido tradicionalmente funciones endoculturales, muchas veces de signo sexista: algunas canciones de corro o comba de las niñas reflejaban aspiraciones muy próximas a la búsqueda de novio, por ejemplo, mientras que las canciones masculinas eran portadoras de actitudes de afirmación violenta y competitividad más marcadas (Pedrosa y Moratalla 2002: 40).

Hay antologías y cancioneros en donde aparecen confundidos los juegos mimicos y las canciones escenificadas, sin duda porque ambos necesitan un soporte gestual para interpretarse. Pero los primeros son juegos sensoriales en los que el niño es sólo destinatario de la cantinela, además de protagonista pasivo de la acción, del que no se espera ninguna respuesta, o al que se quiere provocar, con la retahíla que se le ofrece, una balbuciente repetición, siendo necesaria la intervención de un adulto, que es quien emite la cantinela (Cerrillo 1987): Sin embargo, en las canciones escenificadas la composición se estructura de acuerdo a sus contenidos, en unos casos, o al tipo de juego a que acompaña, o - al menos- a la finalidad con que se interpreta la canción, en otros casos; de ese modo surgen canciones de corro, de comba, de filas, de columpio, de pelota,... 
A veces, una misma tonada es interpretada como juego mímico y como canción escenificada, sin que varíen sus contenidos:

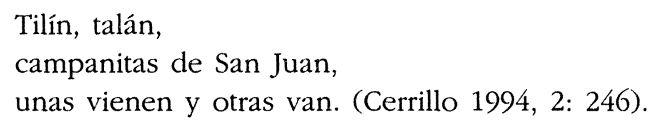

Se trata de un juego mimico de las primeras edades cuando lo interpreta un adulto, quien sienta al niño pequeño sobre sus rodillas y lo balancea adelante y atrás, con las manos cogidas, al tiempo que entona la cantinela. Pero es también una canción escenificada cuando es interpretada por los propios niños, en este caso no tan pequeños, quienes, de dos en dos, con las espaldas de uno contra las del otro y agarrándose fuertemente por los antebrazos o por la cintura, se van levantando alternativamente, imitando el movimiento de balanceo de una campana cuando es volteada para que suene.

En relación a ello, no podemos olvidar que las barreras existentes entre los diversos tipos de composiciones que integran el Cancionero Infantil son bastante permeables: de ahí que haya elementos temáticos que parecen propios de una "canción de corro" pero que los encontramos formando parte de una "suerte"; o elementos característicos de una "nana" que aparecen incluidos en un "juego mímico". (Cf. Cerrillo 1996: 7-16).

SOBRE EL ORIGEN DE ALGUNAS DE ESTAS CANCIONES: EL ROMANCERO Y LA INFANCIA

De sobra es sabido que algunos géneros literarios de transmisión oral murieron cuando finalizaron las circunstancias históricas que habían provocado su aparición y a las que esos géneros daban respuesta: un buen ejemplo son los cantares de gesta, que dejaron de componerse y de demandarse conforme fue finalizando la Reconquista, que era su principal argumento.

Sin embargo, hay otras manifestaciones literarias de transmisión oral que han pervivido durante cientos de años (v.g. los romances) propiciando, incluso, la aparición de nuevas composiciones que, a veces, tienen su origen en aquellos más antiguos. Todavía hoy, en muchos lugares de la geografía española, se siguen interpretando romances, casi siempre con motivo de ocasiones muy particulares: la vendimia, la siega, la recogida de la aceituna o la llegada del mes de mayo, sin que los niños queden al margen de esas actuaciones.

En algunas canciones escenificadas, que -como vimos- son compo- 
siciones de específica tradición infantil, podemos comprobar la supervivencia de algunos romances $\longrightarrow$ de partes de los mismos- como "canciones de comba" o "de rueda" de amplia difusión popular; el mecanismo por el que este hecho se consuma lo explica así Celaya (1981: 219): "Las rondas infantiles extraen de largos romances unos pocos versos que les parecen de evidente impacto".

Ana Pelegrín (1996: 242), por su parte, afirma, con indudable acierto y mayor precisión que Celaya, que esta tendencia a la fragmentación, es un procedimiento recreador característico del romancero infantil: "La fragmentación obra por condensación, despojando al texto de secuencias narrativas [...] Los romances guardan los motivos y tienden a la fragmentación lírica".

Ya Menéndez Pidal (1968, II: 385) se refirió a algunos antiguos romances que siguieron vivos sólo en ciertos juegos escenificados, casi siempre de niñas, afirmando que:

Donde ya todo el romancero está olvidado, quedan aún los niños cantando su pequeño repertorio. La última transformación de un romance y su último éxito es llegar a convertirse en un juego de niños.

"El Infante Arnaldos", "El Conde Olinos", "La doncella guerrera", "Las tres cautivas", "Hilo de oro" o "Dónde vas Alfonso XII", serían algunos casos. Ana Pelegrín localiza la existencia de casi cincuenta temas romancísticos en los juegos infantiles hispánicos, aunque también afirma que en los últimos treinta años el repertorio se ha reducido notoriamente, siendo los más frecuentes "Mambrú", "Don Gato", "La vuelta del marido", o los antes citados "Dónde vas Alfonso XII", "Hilo de oro", "La doncella guerrera" y "Las tres cautivas".

En algunos, como es el caso de "Dónde vas Alfonso XII", encontramos además un buen ejemplo de lo que Luis Díaz G. Viana (1997: 24) llama el "proceso de actualización romancística", por el que a un antiguo romance se incorporan acontecimientos de la realidad más cercana. Veámoslo. Desde hace más de cien años, muchos niños y niñas españoles han cantado, con ligeras variantes, esta canción:

—¿Dónde vas Alfonso Doce?

- Voy en busca de Mercedes

5 - Tu Mercedes ya se ha muerto, cuatro duques la llevaban Su carita era de lirio, el mantón que la cubría Las botitas que llevaba 15 regaladas por Alfonso
¿Dónde vas triste de ti? que ayer tarde no la vi. muerta está, que yo la vi, por las calles de Madrid.

10 sus manitas de marfil, era un rico carmesí. eran de un fino charol, el día que se casó. 
Al subir las escaleras, Al sentir los cañonazos, y oyó una voz que decía: Por el fondo del palacio

25 Cuanto yo más me alejaba, -No te retires, Alfonso, que yo soy tu linda esposa Los faroles de palacio porque Mercedes ha muerto
Alfonso se desmayó.

20 Alfonso salió al balcón, -Señor rey, tened valor. una sombra vio venir. más se venía hacia mí. no te retires de mí,

30 que te vengo a despedir. ya no quieren alumbrar y luto quieren llevar.

[Versión cantada en Cuenca, recopilada por el autor en 1988]

Alfonso XII y Mercedes de Orleans habían formado un matrimonio muy popular en la España de los años setenta del siglo pasado. La muerte de la joven Mercedes en 1878 no sólo entristeció a su joven marido, sino a casi toda España, hasta el punto de incorporarse como contenido al citado romance sólo unos días después de la fecha del fallecimiento de la reina; romance que se entonaba como canción que acompañaba un juego de corro de niñas que ya está referido por Pérez Galdós en uno de sus Episodios Nacionales, "Cánovas", de este pormenorizado modo:

Una tarde de julio ${ }^{1}$, paseando por el Prado, oímos estas coplas, cantadas por las tiernas niñas que jugaban al corro: “¿Dónde vas, Alfonso XII? / ¿Dónde vas, triste de ti?” [...] La simplicidad candorosa de estos versos, en boca de inocentes criaturas, se me metía en el corazón, avivando la doliente memoria de la reina sin ventura, muerta en la flor de la edad.

Otro día, en Recoletos, oí las mismas coplas [...] Recreándonos con tan ingenua cantata dimos la vuelta al corro y pudimos enriquecer el poema infantil con esta otra cuarteta: "El manto que la cubría / era un rico terciopelo, / y en letras de oro decía: / Ha muerto cara de cielo" [...] Esos lindos cantares contienen más inspiración y mayor encanto que las odas hinchadas y las elegías lacrimosas con que los poetas de oficio lamentaron el prematuro fin de Merceditas (Pérez Galdós 1965: 1336).

La versión arriba incluida es una de las varias que han podido fijarse; todas ellas, como bien señala Gabriel Celaya (1981: 200-203), podrían tener su origen en un romance más antiguo que nada tiene que ver con el protagonista de la cantinela, es decir con Alfonso XII, pero del que ésta ha tomado el ritmo, incluso versos completos. El romance originario es un romance novelesco de asunto amoroso, del siglo $\mathrm{Xv}^{2}$, aunque difundido también en el XVI, y conocido con los títulos de "El palmero" o "La

\footnotetext{
${ }^{1}$ Se refiere Galdós al mes de julio del mismo año, es decir unos días después de la muerte de Mercedes, que tuvo lugar el 25 de junio.

${ }^{2}$ Recogido por SEPÚlvEDA. Romances nuevamente sacados... (Cf. Durán 1945).
} 
aparición"; en él se contaba la historia de un caballero que se encontraba con su amada muerta, en forma de espectro. Ésta es una de las versiones más conocidas:

En los tiempos que me vi yo me partiera de Burgos

5 Encontré con un Palmero, - ¿Dónde vas tú, el desdichado? ¡Oh persona desgraciada, Muerta es tu enamorada, las andas en que la llevan

15 los responsos que le dicen siete condes la lloraban, llorábanla sus doncellas, —iTriste de aquel caballero ' Desque aquesto oí, mezquino,

25 y por más de doce horas Desque hube retornado con lágrimas de mis ojos -Acógeme, mi señora, Al cabo de la sepultura

35 -Vive, vive, enamorado, Dios te dé ventura en armas, que el cuerpo come la tierra más alegre y placentero, para ir a Valladolid. quien me habló y dijo así: ¿Dónde vas? ¡Triste de ti!

10 en mal punto te conocí! muerta es, que yo la vi; de negro las vi cubrir, yo los ayudé a decir: caballeros más de mil,

20 llorando dicen así: que tal pérdida pierde aquí! en tierra muerto caí, no tornara, triste, en mí. a la sepultura fui,

30 llorando decía así: acógeme a par de ti. esta triste voz oí: vive, pues que yo morí: y en amor otro que sí, 40 y el alma pena por ti.

Estudio DE UN EJEMPLO SIGNificativo: "Hilo DE ORO"

Otro ejemplo, muy significativo, sería el de "Hilo de oro", que trata de un tema recurrente en el Romancero, el de la elección amorosa, y que pervive como canción escenificada infantil tanto en España como en Latinoamérica, en diferentes versiones que afectan, incluso, a su verso inicial: "A la cinta, cinta de oro", "Anillito de oro", "Piso oro, piso plata", "Cordoncito de oro", "De Francia vengo, señores", "De Francia vengo, señora". Rodríguez Marín (1932: 55) afirmó que el romance ya era conocido en el siglo XVI y que en el XVII se representaba como juego; Margit Frenk (1987: 1031-1032) recoge una versión de la que dice que su fuente es un baile anónimo, Baile curioso de Pedro de Brea (1616). En la acotación previa al baile se dice: "Salen los músicos con sus guitarras y algunas damas con ellos, divídanse en dos corros y siéntanse diciendo [...]" (Cotarelo 1911: 479b); y en el desarrollo del propio baile, podemos leer versos como éstos, de fácil identificación en cualquiera de las versiones que se conservan vivas: "Si una de estas doncellas / que tenéis alrededor / queréis por mujer darme, / mi suerte alabo yo" (Cotarelo 1911: 480a); o 
como éstos otros: "Yo me voy muy enojado / a los palacios del rey, / que la hija del rey moro / no me la dan por mujer" (Cotarelo 1911: 480b).

Por su parte, Ana Pelegrín (1996: 272-273) dice que en el XVII lo mencionaron también Lope de Vega y Tirso de Molina, lo que pudiera entenderse como un claro indicio de que era conocido popularmente ya entonces. De todos modos, será en el siglo XIX cuando empiecen a aparecer las primeras versiones fijadas por escrito. Veamos la que se guarda en el Archivo del Seminario Menéndez Pidal ${ }^{3}$, recogida en 1929 en Alcolea del Río (Sevilla) por Eduardo Martínez Torner:

-De Francia vengo, señora me han dicho en el camino

5 -Que las tenga o no las tenga con un pan que Dios me ha dado - A Francia vuelvo señora que las hijas del rey moro -Vuelva, vuelva caballero

15 de las tres hijas que tengo -Esta tomo por esposa que ha parecido una rosa -Lo que tengo que rogarle -Bien tratadita estará

25 sentada en silla de plata azotitos con correas y una perita en la boca traigo un hijo portugués que lindas hijas tenéis. yo las sabré mantener otro que lo ganaré.

10 a los palacios del rey no me las dejaron ver. no sea tan descortés, tome la que guste usté. ésta tomo por mujer

20 me ha parecido un clavel. es que me la trate bien. y bien comida también, bordando encajes al rey cuando sea menester

30 a las horas de comer.

Es una versión de treinta versos en los que se establece un diálogo entre un caballero y la madre de las hijas del rey moro; el caballero, que, de oídas, tiene muy buenas referencias, pretende a una de las hijas. Tras una primera negativa de la madre (probablemente se trata de una convención propia de la primera petición) y ante la decisión del caballero de no insistir (en forma de reacción airada, quizá también convencional), la madre reconsidera su respuesta y le dice que elija entre las tres hijas: el caballero elige y, a partir de ese momento, el diálogo trata del cuidado que le dispensará a la muchacha.

Rodríguez Marín (1932: 56) describe así el juego:

Colócanse varias niñas en hilera, sentadas en el suelo, cada una entre las piernas de la anterior, a la que vuelve, naturalmente, la espalda; la última de la fila hace el papel de madre, y las demás son sus hijas. Así colocadas, llega un niño o niña, que hace de embajador [caballero], entre el cual y la madre se entabla el diálogo siguiente [...]

\footnotetext{
3 Citado por Pelegrín (1996: 274).
} 
En su práctica como canción escenificada infantil, es un juego dialogado, repetitivo, de elección y, por tanto, de eliminación, por el que las niñas intervinientes que van asumiendo, sucesivamente, el papel de hija elegida por el caballero, van siendo eliminadas. En el Cancionero Infantil son frecuentes las canciones escenificadas que conllevan una elección: "La jardinera", "La viudita del Conde Laurel", "Arroz con leche", "Al olivo subí", "Estaba una pastora", "La carbonerita", etc. Esa característica, junto a la tendencia a la fragmentación antes comentada, es la que provoca la existencia de versiones más breves. Veamos dos de las de "Hilo de oro": la primera se recogió en la localidad albacetense de El Cubillo ${ }^{4}$ (Fraile 1993: 52), y consta de sólo veinte versos:

Piso oro, piso plata, que en el camino me han dicho

5 -Si las tengo o no las tengo que del pan que yo comiese - Ya me voy muy enfadado a contarle a mi señora -Vuelva, vuelva, caballero,

15 De las tres hijas que tengo -Ésta escojo por bonita, me ha parecido una rosa piso puntas de alfiler, que buenas hijas tie usté. no las tengo para dar, ellas también comerán.

10 a los palacios del rey lo que me ha ocurrido hoy. no vayas tan descortés. escoge la más mujer. por bonita y por mujer; 20 acabada de coger.

La segunda, aún más corta (sólo catorce versos), es de Villarrubia de los Ojos (Ciudad Real) y la fijó Arturo Medina (1987, 2: 77) con el título de "La hoja verde":

-A la hoja, la hoja verde, que me ha dicho mi madre

5 -A la hija del rey moro

$\mathrm{Ni}$ es por guapa, ni es por fea,

-A ésta no la quiero

A ésta me la llevaré

Parece una rosa,

\begin{abstract}
a la hoja del verde laurel, cuántas hijas tiene usted. no la quiero yo ni ver. ni es por punta de alfiler.

10 por fea y por pelona. por guapa y por hermosa. parece un clavel.
\end{abstract}

Algunas de las singularidades más llamativas de ese proceso de apropiación de ciertas composiciones por parte de los niños son: la ya comentada tendencia a la fragmentación de la composición original, el intercalado de estribillos que faciliten la memorización (de lo que hablaremos más adelante) y una cierta contaminación con elementos extraños a la historia original, que puede llegar a provocar ciertas deformaciones expresivas y algunos sinsentidos. Fijémonos en algunos ejemplos:

${ }^{4}$ Cantada por Araceli Pallarés Marín, de 72 años de edad; recopilada el 14 de marzo de 1983 por Vicente Ríos y Ángel López. 
Los dos primeros versos de la versión de Torner dicen:

De Francia vengo, señora, traigo un hijo portugués [...]

En otra versión, citada por Pelegrín (1998: 199-200), se dice:

De Francia vengo, señores,

de por hilo portugués [...]

Parecería más lógico que fuera "hilo" y no "hijo": tiene sentido "hilo portugués", ya que era un hilo muy valorado y reconocido en el siglo XviI. Pero la deformación es más llamativa en otros casos, en los que llegan a aparecer expresiones sin un significado lógico, como en esta versión de El Ballestero (Albacete), recopilada en 1983 por Concepción Vázquez (Fraile 1993: 51):

De Francia vengo, señores,

un poquito por su bien [...]

También es una versión notablemente contaminada la que recogen Raquel Calvo y Raquel Pérez (2003: 88), sobre todo en las explicaciones que el caballero da para elegir a una de las hijas y no a las otras (versos 17 a 23), que es, además, la parte en que se abandona el octosílabo, mantenido hasta ese momento regularmente:

A la cinta, cinta de oro, en el camino me han dicho:

5 -Que las tenga o no las tenga, - Yo me voy muy enojado a contárselo a la reina que las hijas del rey moro ni por oro, ni por plata,

15 ni por dinero que valga -Ésta no la quiero a ésta me la llevo parece una rosa, acabado de nacer.

25 que me la cuide usted bien. sentadita en silla de oro con la manzana en la boca a la hoja de laurel, -iQué buenas hijas tié usted! iqué se le importará a usted! a los palacios del rey

10 y a la infanta doña Inés, no me las quieren vender ni por punta de alfiler, la corona de Isabel. porque es pelona,

20 por linda y hermosa; parece un clavel

- Lo que le encargo, caballero, -Bien cuidadita estará, bordando paños al rey,

30 a la hora de comer.

En otras ocasiones, a la contaminación se suma una fragmentación excesiva, que más parece consecuencia de un fallo de memoria del informante que el resultado del propio devenir de la canción en su uso como canción escenificada infantil; sería el caso de la versión recogida en Pue- 
bla (México), en 1904, y fijada con el título "Ángel de oro" por el folclorista Vicente T. Mendoza (1980: 125), que finaliza con la elección de la hija, desapareciendo de la composición el diálogo final sobre los cuidados que el caballero dispensará a la chica:

Ángel de oro, que de Francia he venido

5 Que me ha dicho una señora -Que las tenga o no las tenga Ésta me la llevo parece una rosa Ésta no la quiero

15 parece una mona Ésta me la llevo parece una chaquira arenita de un marqués, por un niño portugués. que lindas hijas tenéis. o las deje de tener.

10 por linda y hermosa, acabada de nacer. por fea y pelona, acabada de nacer. parece un clavel,

20 acabada de nacer.

\section{SOBRE LOS CONTENIDOS DE LAS CANCIONES ESCENIFICADAS}

El objetivo esencial de este tipo de canciones favorece, en muchos casos, la presencia de algunos elementos temáticos. En principio, ya lo dijimos, son canciones que acompañan la ejecución de un juego o acción escenificada, en donde destaca el ritmo, aunque - a veces- éste puede quedar eclipsado por la densidad de contenidos o por la originalidad del desarrollo del juego. El esquema general de la comunicación -o ejecución- lo establece la propia dinámica del juego o acción: un colectivo de muchachos o muchachas, más o menos numeroso, juega o escenifica con el apoyo textual y rítmico de la canción. El papel del emisor puede cumplirlo uno solo del grupo, el grupo completo o repartirse las intervenciones, alternándolas en diálogo a dos voces.

Aunque predominan las composiciones en que el texto es un mero sostén rítmico para la ejecución de gestos y acciones mimadas muy concretas, es necesario referirse a algunos de los temas que se tratan, sobre todo en aquellos casos en que son determinantes para la comprensión global de la canción. Por esta razón, es conveniente fijar dos grupos distintos de canciones.

En el primero de ellos, incluiríamos aquéllas en las que los temas están en función del juego al que acompañan; de ahí que nos podamos encontrar con meras descripciones de la propia acción, no siempre comprensibles en su conjunto:

Al juego chirimbolo, ¡qué bonito es! 


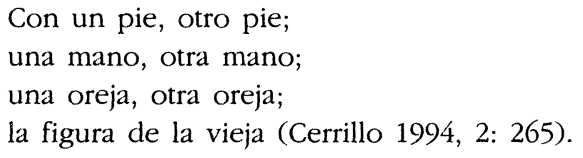

Como se puede apreciar, en esta canción la historia se construye, con más o menos sentido, sobre el desarrollo de las acciones consecutivas que el propio juego exige. En esta línea, incluso nos encontramos con canciones que son verdaderos "sinsentidos", plagadas de contenidos absurdos:

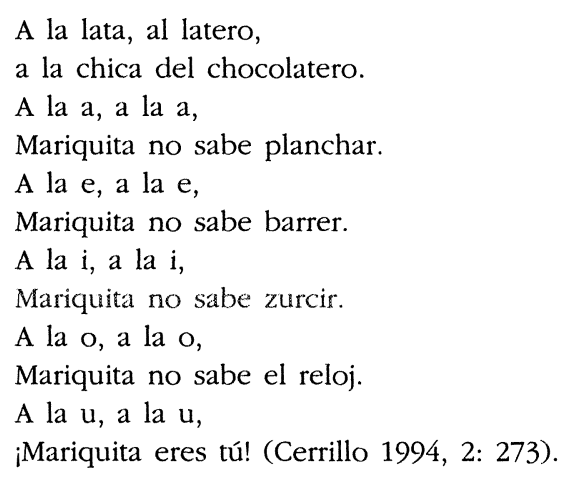

Pero hay un segundo grupo de canciones, apreciable en número, en las que la base textual porta elementos temáticos más precisos; de tal modo que nos encontramos canciones escenificadas en las que se cuenta una historia, con su principio y su final, plenamente desarrollada ("Al salirme de La Habana...", "A mi burro", "Estaba una pastora", "Una tarde fresquita de mayo" o "Estaba el señor don Gato"). De todos modos, estos contenidos, aunque hay excepciones - sobre todo las que representan las canciones que proceden de romances-, tienen un carácter notablemente circunstancial: me refiero a que, pese a la existencia de esas historias, lo que queda de esas canciones suele ser el ritmo, el sonsonete, la acción que se escenifica, la plasticidad o el movimiento, antes que la propia historia. Curiosamente, en muchas de las excepciones a que antes nos referíamos el asunto es amoroso, aunque en estos casos solemos encontrarnos versiones muy diferentes en su desenlace:

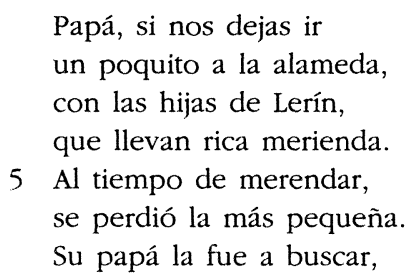


calle arriba, calle abajo, calle de Santo Tomás;

10 y hablando con su muñeca la ha encontrado en un portal. (Cerrillo 1994, 2: 282).

Celaya (1981: 175) recoge este otro final, a partir del verso 7 , sin duda más "problemático" para una canción infantil:

Su padre la fue a buscar, cuando al volver una esquina, ¿dónde la vino a encontrar?

10 En un portalillo oscuro hablando con su galán, y estas palabras decía: - Contigo me he de casar, aunque me cueste la vida.

\section{SOBRE LA ESTRUCTURA ORGANIZATIVA DE ESTAS CANCIONES}

No es perceptible un esquema claro en la organización de los contenidos de estas composiciones; sí hay, sin embargo, una serie de recursos que afectan —en mayor o menor medida - a la ordenación de los elementos de cada canción y que, fundamentalmente son éstos:

\section{a) Fórmulas de inicio y fórmulas de final}

En ellas podemos ver una trasposición de mecanismos que son habituales en el cuento tradicional que se utilizan para iniciar -indeterminadamente - una historia: "Estaba una pastora...", "Érase una vieja...", "Estaba el señor don Gato..."; o para finalizarla con contundencia: "[...] y el cuento se acabó".

\section{b) Los diálogos}

Aunque no son frecuentes - salvo en las canciones que tienen "elección"-, a veces se incluyen intervenciones alternativas de dos o más personajes:

$$
\begin{aligned}
& \text {-Chica, ¿a dónde vas? } \\
& \text { —Chica, a la botica. } \\
& \text { —Chica, ¿qué te pasa? [...] }
\end{aligned}
$$


En los casos de "elección", los diálogos son representados mediante la asunción de papeles específicos por los intervinientes:

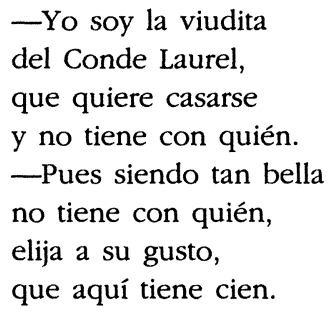

\section{c) Repeticiones}

Son muy frecuentes, y no sólo porque están en función del logro, por sí mismas, de un determinado ritmo:
A la lima, a la limón,
la fuente se ha caído.
A la lima, a la limón,
mandadla componer.

A la lima, a la limón [...]

Sino también porque esas repeticiones aportan particularidades específicas a la estructura de estas composiciones. Veámos las repeticiones más frecuentes:

c.1. Por encadenamiento de estrofas o grupos de versos. Bien repitiendo un elemento de una estrofa en la siguiente:

$$
\begin{aligned}
& \text { [...] de nadie me despedí, } \\
& \text { sólo de un perrito chino } \\
& \text { que andaba detrás de mí. } \\
& \text { El perro, como era chino [...] }
\end{aligned}
$$

Bien repitiendo el término final de una estrofa a comienzo de la siguiente:

$$
\begin{aligned}
& \text { [...] para ver los soldados } \\
& \text { de Cataluña. } \\
& \text { De Cataluña vengo, [...] }
\end{aligned}
$$

Bien, encadenando completamente las estrofas, mediante la repetición completa del último verso de una, al inicio de la siguiente:

$$
\begin{aligned}
& \text { El carbonero } \\
& \text { por las esquinas } \\
& \text { va pregonando } \\
& \text { carbón de encina. }
\end{aligned}
$$




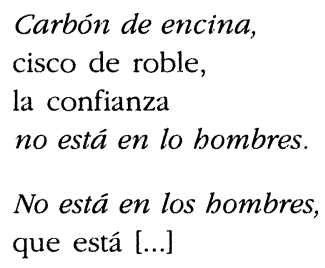

O bien, repitiendo, en forma de anáfora, la misma conjunción a comienzo de cada estrofa:

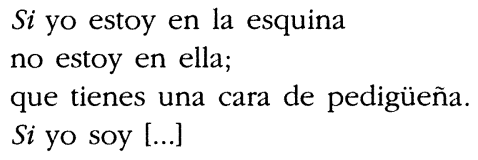

c.2. Por encadenamiento de versos:
A la lima, a la limón,
la fuente se ha caído.
A la lima, a la limón, mandadla componer.
A la lima, a la limón [...]

c.3. Por la creación de estribillos.

En la mayoría de las ocasiones, los estribillos se forman mediante la repetición de palabras que tienen ciertos valores sonoros, sin significados aparentes pero con una gran eficacia rítmica: Carabi urí, carabi urá; chúngala, chúngala, chúngala; tras-tras; lairón, lairón, lairón. Esas construcciones llegan, incluso, a provocar verdaderos trabalenguas: ¡Teca, meca, chibiringorda! En algunas composiciones se concentran dos o más estribillos distintos, de modo que pueden llegar a oscurecer al resto de los elementos que las componen:

\author{
La chata Merenguela, \\ igüi, güi, güi!, \\ como es tan fea, \\ ¡trico, trico, tri!, \\ como es tan fea, \\ ¡lairón, lairón, lairón, \\ lairón, lairón! [...]
}

Sobre la frecuente aparición de estribillos, explica Ana Pelegrín (1996: 233) que:

La memoria colectiva precisa momentos de estabilización, de reiteraciones aseguradoras, para ello utiliza la repetición, el estribillo, que responde a la exigencia colectiva de organizar las voces en simultaneidad, facilitando la memorización de los poemas cantados. 
Aunque en las canciones escenificadas aparecen rasgos que son también propios de otros tipos de composiciones del Cancionero Infantil (verso de arte menor, rima regulada o recursos formales de carácter repetitivo, como la onomatopeya, la anáfora, el polisíndeton o el paralelismo), el lenguaje de estas canciones está enriquecido por la presencia de un variado sistema metafórico. No obstante, y como suele ser general al conjunto del Cancionero Popular Infantil, el especial ritmo de estas canciones es, a menudo, tan marcado, que llega a convertirse en la base sobre la que se construye todo el poema; al respecto, no podemos olvidar que la acción que conllevan estas tonadas se concreta en variados movimientos y gestos, que, pueden dar lugar, en algunos casos, a una incipiente representación.

ORALIDAD Y ESCRITURA. HACIA UN NUEVO APRENDIZAJE DE LA CANCIÓN ESCENIFICADA

El proceso de desaparición que sufren estas composiciones provoca, simultáneamente, la pérdida de su vertiente lúdica. Los niños de hoy aprenden algunas de estas canciones en el ámbito escolar, memorizando las versiones que aparecen en sus libros de texto, aprendiéndolas como textos literarios y no como juegos.

En la escuela, el trasvase de lo escrito a la voz, de lo impreso a la memoria oral del grupo de niños, se configura como una peculiar fijación del texto. La relación del texto impreso y el repertorio infantil requiere un análisis detallado, teniendo en cuenta las versiones de romances impresos en textos escolares, libros de lectura, cancioneros musicales para las escuelas y otros romances divulgados en publicaciones periódicas, en libros de juegos y entretenimientos. (Pelegrín 1996: 256).

Por ello, diversas consideraciones filológicas, incluso críticas, nos llevan a plantear la duda del sentido que pudiera tener el tratamiento como texto escrito de un material de transmisión y pervivencia orales. El problema ha llevado a algunos estudiosos y folcloristas a retrotraerlo al momento mismo de la invención de la imprenta (Mendoza Díaz-Maroto 1989: 53-57), referido al romance tradicional, sobre todo, en el sentido de que aquélla le causó más males que bienes, porque si bien ayudó a salvar muchas composiciones, lo hizo por un interés comercial, imponiendo unos criterios muy concretos, según los cuales las colecciones o antologías no respondían a los gustos del público de "a pie", sino a los de una minoría ilustrada. El hecho, aun siendo cierto, pues algunos romances de indudable trascendencia para el Cancionero Infantil, por estar en el origen de algunas canciones - los del "Conde Niño" o "Delgadina"-, los hemos co- 
nocido en versiones manuscritas y no como resultado de la gran tarea de fijación que se llevó a cabo en el siglo XVI, hay que asumirlo como un hecho histórico que es: la imprenta, desde fines del siglo $\mathrm{xv}$, ofreció la posibilidad de fijar unos textos, con algunas de sus posibles variantes, que vivían libremente en la tradición oral, pero que con su fijación escrita entran de lleno en el campo de la literatura, debiendo ser estudiados y tratados como textos literarios que son, con todas sus peculiaridades lingüísticas y estilísticas. Lo que sucede es que el hecho, en sí mismo, vulnera las reglas del juego; Diego Catalán (1969: 8) se refiere a la labor de la imprenta del siglo XVI que, en muchos casos:

Logró legar al mundo literario unos poemas "tradicionales" aparentemente "perfectos", "acabados". Nuestra imagen del Romancero se halla deformada por esta labor de los impresores del siglo XVI, pues un poema tradicional es, por esencia, "imperfecto".

Se ha llegado a decir que esa fijación escrita es una traición al carácter oral de esa poesía, porque desvirtúa su esencia, su propia tradición colectiva que le permite vivir en continua reelaboración; lo que sucede es que dicha fijación es una labor necesaria y, además, urgente, debido a las presiones a que está sometida, como consecuencia de los tremendos cambios que se han producido en las sociedades contemporáneas más avanzadas, y que afectan a todos los órdenes de la vida, pero especialmente a sus medios de comunicación.

El paso de la oralidad a la escritura de ese tipo de composiciones puede provocar en muchos niños, aunque también en adultos, el descubrimiento de la magia de la que muchas palabras suelen ser portadoras. Luis Landero se refiere al protagonista de su libro Entre líneas: el cuento o la vida, cuando el adolescente descubrió que cualquier palabra podía ser mágica, y dice (Landero 2001: 146):

Leía por ejemplos "voy soñando caminos de la tarde", y esas palabras tan humildes, tan al uso, "caminos", "tarde", eran de pronto nuevas y poderosas, tanto o más que las del cuento del genio y del tesoro.

Lo mismo sucede, en ocasiones, con textos del Cancionero Infantil, cuando se pasa de la identificación automática de una canción con el juego a que acompaña (de comba, de filas, de columpio, de corro), a la emoción que transmite la historia contenida en la canción: sirvan como ejemplo las conocidas historias que han hecho muy populares ciertos romances ya comentados aquí. La memoria nos proporciona identidad cuando pasamos de la oralidad a la escritura: el texto que en la transmisión oral era sólo, o sobre todo, soporte de un juego, al pasar a la escritura necesita desentrañamiento y comprensión. 
Ya que, como decimos, muchos de estos textos son aprendidos hoy por los niños en el ámbito escolar, me permitiré una referencia final sobre el aprovechamiento didáctico que se pudiera hacer de ellos.

Cuenta Ana Pelegrín (1982: 16) una anécdota muy significativa: la de una niña de Zamora a la que su profesora había exigido la memorización del romance del "Conde Olinos" que, en versión de Menéndez Pidal, venía en su libro de texto. Cuando se le requirió el recitado, al pie de la letra, la niña comenzó con "Madrugaba el Conde Olinos / mañanita de San Juan...", pero de pronto y entre vacilaciones, se apartó de la versión incluida en su libro y, con mayor seguridad y aplomo, continuó diciendo otra versión que ella había escuchado con anterioridad de boca de su abuela. Efectivamente, a la niña le "sonaba" ese romance y enseguida lo asoció al que su abuela le había enseñado, que era el mismo, pero con algunas diferencias. El romance había vuelto así a su origen, al caudal oral de la lírica popular: la niña había descubierto $y$, al mismo tiempo, había provocado que todos descubrieran - también su profesora- el proceso de la tradicionalidad.

El potencial educativo de los materiales folclóricos es muy grande, no sólo en lo que pueda tener de aprendizaje activo (recogida mediante trabajo de campo), sino también en sus relaciones con el contexto, que permitirán a los alumnos interesarse por las costumbres, fiestas, tradiciones o creencias de su entorno más cercano. La programación de actividades escolares con el folclore infantil ofrece posibilidades didácticas interesantes, tanto en el ámbito de lo social como en el de lo literario. En el primero de ellos, y sólo en lo referido a la recuperación de materiales literarios de tradición oral, el folclore infantil aportará a los niños conocimientos sobre creaciones que estaban vivas en generaciones anteriores, mediante las que pueden comprender aspectos de la vida cotidiana pasada y elementos que pertenecen a su identidad como pueblo, o como región, o como, incluso, miembros de una misma comunidad idiomática.

Como señala Díaz G. Viana (1997:18):

La cultura popular nos enseña que muchos de nuestros abuelos y demás antepasados sabían más que nosotros sobre lo que realmente debían saber, aunque apenas pudieran garabatear su nombre, porque habían llegado a adquirir un cabal visión del mundo, del hombre y de las cosas.

Aunque hoy ya no es fácil que los chicos puedan "pasarlo mal" como lo pasaban los mozalbetes de hace cuarenta años cuando accedían a jugar con las chicas a la "comba rápida" o a escenificar "La Chata Merenguela"; aunque hoy ya no veamos en calles y plazas a niñas jugando a diversos corros y ruedas, o a adolescentes arrearse golpes jugando al 
"Moscardón"; aunque esas prácticas y juegos son casi un resto arqueológico de una tradición finiquitada, no está mal que niños y niñas de hoy puedan acceder a los contenidos de esos textos, aunque sea por una vía desnaturalizada, ya que son juegos que desarrollan la memoria y que requieren habilidad, atención y socialización: con ellos se aprende a respetar el turno de juego, a ganar y a perder, o a valorar las habilidades del contrario, lo que no es poco en este tiempo en que vivimos.

\section{BIBLIOGRAFÍA CITADA}

Calvo, Raquel y Raquel Pérez. 2003. Pinto, pinto, gorgorito. Retabilas, juegos, canciones $y$ cuentos infantiles antiguos. Madrid: Sammer, $2^{\mathrm{a}}$ ed.

Catalán, Diego. 1969. Siete siglos de Romancero. Madrid: Gredos.

- 1970. Por campos del Romancero. Estudios sobre la tradición oral moderna. Madrid: Gredos.

Celaya, Gabriel. 1981. La voz de los niños. Barcelona: Laia.

Cerrillo, Pedro C. 1987. "Literatura y folklore en los juegos mímicos infantiles". Revista de Dialectología y Tradiciones Populares XLII: 97-108.

- 1994. Lírica popular española de tradición infantil. Cuenca: Universidad de Castilla La Mancha, 2 vols.

- 1996. "El Cancionero Popular Infantil Español. Algunas consideraciones sobre su estructura, formas y ritmo". Amigos del Libro (Revista de la Asociación Española de Amigos del Libro Infantil) XIV, 31: 7-16.

COTARELO MORI, E. 1911. Colección de entremeses, loas, bailes, jácaras y mojigangas. Madrid: Biblioteca de Autores Españoles, vol. II.

Díaz G. Viana, Luis. 1997. Juego de niños. Oyarzun: Sendoa.

DURÁN, AGUSTÍN. 1945. Romancero General o Colección de romances castellanos anteriores al siglo XVIII. Tomo X. Madrid: Biblioteca de Autores Españoles.

FraILE, José M. 1993. "Un muestreo en la poesía tradicional de la Mancha Baja". Zabora 33: $45-57$.

FRENK, MARgIT. 1987. Corpus de la antigua lírica popular hispánica. Siglos XV a XVII. Madrid: Castalia.

LANDERO, LUIS. 2001. Entre líneas: el cuento o la vida. Barcelona: Tusquets.

Medina, ARTURo. 1987. Pinto Maraña. Juegos populares infantiles, 2 vols. Madrid: Miñón. MENDOZA, Vicente, T. 1980. Lírica infantil de México. México: FCE, $2^{\mathrm{a}}$ ed.

MENDOZA DÍAz-MAROTO, F. 1989. Introducción al Romancero oral de la provincia de Albacete. Albacete: Diputación de Albacete.

MENÉndez Pidal, Ramón. 1968. "Los juegos infantiles". Romancero Hispánico, vol. II. Madrid: Espasa Calpe: 385-388.

Pedrosa, José M. y S. Moratalla. 2002. La ciudad oral. Madrid: Consejería de Educación, Comunidad de Madrid.

PElegrín, ANA. 1982. La aventura de oir. Madrid: Cincel.

- 1996. La flor de la maravilla. Madrid: Fundación Germán Sánchez Ruipérez.

- 1998. Repertorio de antiguos juegos infantiles. Madrid: CSIC.

PÉrez Galdós, B. 1965. Episodios Nacionales, vol. III. Madrid: Aguilar, $7^{\mathrm{a}}$ ed.

RODRíGUEZ MARÍN, F. 1932. Pasatiempo folklórico. Varios juegos infantiles del siglo XVI. Madrid: Tipografía de Archivos. 